\title{
Cryogenics for the LEP200 Superconducting Cavities at CERN
}

D.Güsewell, M.Barranco-Luque, S.Claudet, W.K.Erdt, P.Frandsen, Ph.Gayet, J.Schmid, N.Solheim, Ch.Titcomb, G.Winkler CERN, CH-1211 Geneva 23, Switzerland

\begin{abstract}
The cryogenics for the LEP200 Project cover the cooling requirements of up to 64 modules containing each four superconducting (SC) cavilies at $352 \mathrm{MHz} R F$. This includes bath cooling for the cavities themselves by liquid helium boiling at $4.5 \mathrm{~K}$, and use of cold helium gas for intercepting heat from accessories. Helium refrigeration is provided by separate powerful cryoplants at each of the four interaction points of LEP with $12 \mathrm{~kW}$ equivalent refrigeration at $4.5 \mathrm{~K}$ and cryogenic distribution lines of up to $810 \mathrm{~m}$ length, and by two $6 \mathrm{~kW}$ plants for the new test center SM18 where the acceptance tests of both SC cavities and magnets are carried out. Most of the hardware is installed, commissioning of the systems in LEP is progressing and experience in testing the new cavities from industry is accumulating. First conclusions and performance results are reported, and problems listed which require further work.
\end{abstract}

\section{INTRODUCTION}

The LEP200 Project was started at CERN in 1989. By 1995 192 SC cavities should be operational in LEP to boost the $\mathrm{e}^{+} / \mathrm{e}^{-}$energy above the $\mathrm{W}^{ \pm}$threshold. The status of the Project is summarized elsewhere at PAC93 [1], and recent results from cavity testing are presented [2]. This paper gives an updated status of the cryogenics for this collider cavity program; a more detailed description was given at ICEC.14 [3].

Special solutions had to be adopted to integrate this new largescale cryogenics into the existing LEP environment without requiring additional underground civil engineering. The LEP200 systems will increase the helium cooling power at CERN almost by an order of magnitude and use about $23 \%$ of the 300 MCHF LEP200 Project funds. Compatibility with the operation techniques developed for the numerous smaller refrigerator plants running since years at CERN and contract splitting to avoid dependence on a single vendor were other management targets which determined basic technical choices.

\section{COOLING REQUIREMENTS OF THE LEP200 CAVITIES}

For the energy upgrade of LEP to approach $90 \mathrm{GeV}$, initially forty-eight 4-cavity modules will be installed in the straight sections of LEP, four on each side of points 2 and 6 , and eight on each side of points 4 and 8 [1]. At a later stage, points 2 and 6 may also be brought to $8+8$ modules.

The LEP200 cavities are cooled by a bath of boiling liquid helium (LHe), operated slightly below 1.3 bar or $4.5 \mathrm{~K}$. A few percent $(0.2 \mathrm{~g} / \mathrm{s}$ per cavity) of the evaporated helium is used for intercepting heat conducted along RF couplers, the beam pipe transition to room temperature and the nickel bars used for frequency tuning, before returning at ambient temperature to the refrigerator.
The cryogenic system of the LEP200 cavities was designcd to cover the thermal load estimates given in Table 1.

Table 1

Refrigeration load design figures per 4-cavity module

\begin{tabular}{|lc|}
\hline $\begin{array}{l}\text { Static losses } \\
\text { Share of distribution losses } \\
\text { Refrigeration equivalent of gas cooling } \\
\quad \text { Conversion } 125 \mathrm{~W} \text { per } 1 \mathrm{~g} / \mathrm{s})\end{array}$ & $<90 \mathrm{~W}$ \\
RF losses at standard RF conditions & $<60 \mathrm{~W}$ \\
$\quad$ (Ref.field of $5 \mathrm{MV} / \mathrm{m}$ with $\left.\mathrm{Q}=3.10^{9}\right)$ & $100 \mathrm{~W}$ \\
$\begin{array}{l}\text { Spare capacity to cover higher field } \\
\text { values or reduced surface quality }\end{array}$ & $200 \mathrm{~W}$ \\
TOTAL & $>300 \mathrm{~W}$ \\
\hline
\end{tabular}

\section{BASIC FEATURES OF THE CRYOGENIC SYSTEM}

The cryogenic system for the LEP200 Project was mainly designed to cover the LHe bath cooling requirements of up to $4 \times 64 \mathrm{RF}$ cavities, made either from niobium $(\mathrm{Nb})$ sheet or $\mathrm{Nb}$ sputtered on copper; but it includes already all features to make its main components also suitable for a future protonproton collider (LHC) in the LEP tunnel.

A major constraint was to avoid new underground civil cngineering work in LEP, but to integrate the cavity cryogenics into the existing shaft and tunnel infrastructure of I.EP. To allow contract splitting after competitive tendering in CERN member countries and to keep the new systems compatible with the operation practice for the existing refrigerators, CERN ordered control hardware and software separately $(\mathrm{ABB}, \mathrm{CH} / \mathrm{S})$. An energy saving design was encouraged by a bonus/malus system including electricity cost over 10 years of running. This led to proposals using 6-8 turbines at different temperature levels between 200 and $4.5 \mathrm{~K}$.

Due to the depth $(50-150 \mathrm{~m})$ of the LEP machine tunnel and the need to operate the cavity bath at constant pressure slightly above atmospheric, LHe production at ground level and the associate static head effects of cold helium had to be excluded.

As a first step, for the prototype cavity string at LEP point 2 and the reception test hall SM18, two very compact $6 \mathrm{~kW}$ refrigerators were ordered in May 1990, one each from SULZER (CH, now LINDE) and L'AIR LIQUIDE (F). This was following the concept of an 'horizontal split' with installation of compact cold boxes in both service tunnels close to the cavity strings.

In 1990 the basic concept was changed to better match LHC requirements and to overcome the $2 \times 6 \mathrm{~kW}$ limitation given by the space in the service tunnels. A novel concept of a 
'vertical split' of the cold boxes near the access shaft was adopted, with a potential of later reaching at least $18 \mathrm{~kW}$ of cooling power at $4.5 \mathrm{~K}$.

Four such $12 / 18 \mathrm{~kW}$ cryoplants were ordered in December 1990, two each from SULZER/LINDE and L'AIR LIQUIDE, including screw compressors for all LEP200 cryoplants from the same manufacturer STAL (SE).

The screw compressors and their gas purification system are installed in separate sound-proofed buildings near the LEP access shafts. Each compressor set consists of 2-4 low pressure (LP) and 1-2 high pressure (HP) units, with variable flow in the $30-100 \%$ range and a recovery mode using only one unit to limit electric power requirements. All cryogenic components working above about $20 \mathrm{~K}$ were grouped into an "Upper Cold Box" (UCB), which could be integrated into the existing surface buildings covering the access shaft (Figure 1).

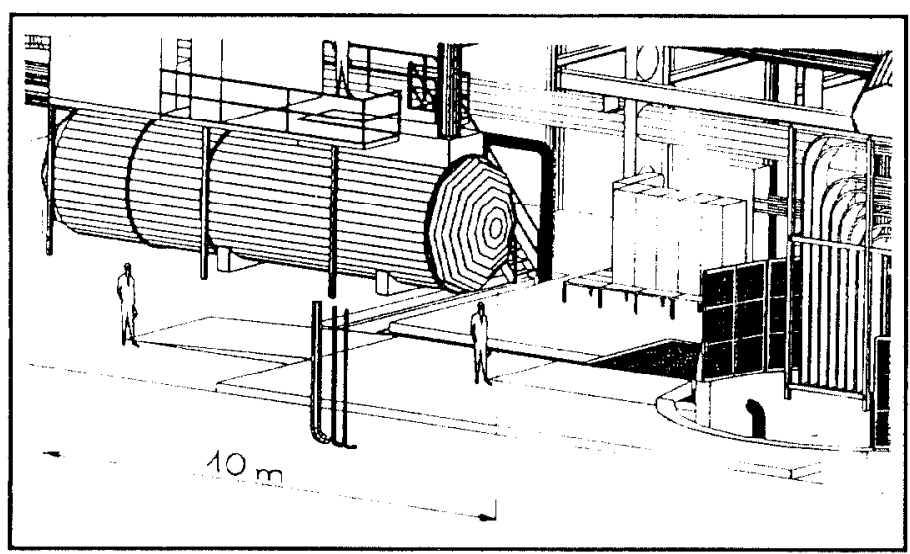

Figure 1

Integration of Upper Cold Box at top of LEP shaft

Although the space limitations in the surface building were not as stringent as for the compact $6 \mathrm{~kW}$ cold box installed in the tunnel, the UCB had to be of horizontal construction too, and use horizontal heat exchangers, but its dimensions were not critical (typical weight $50 \mathrm{t}$, including 4 turbines).

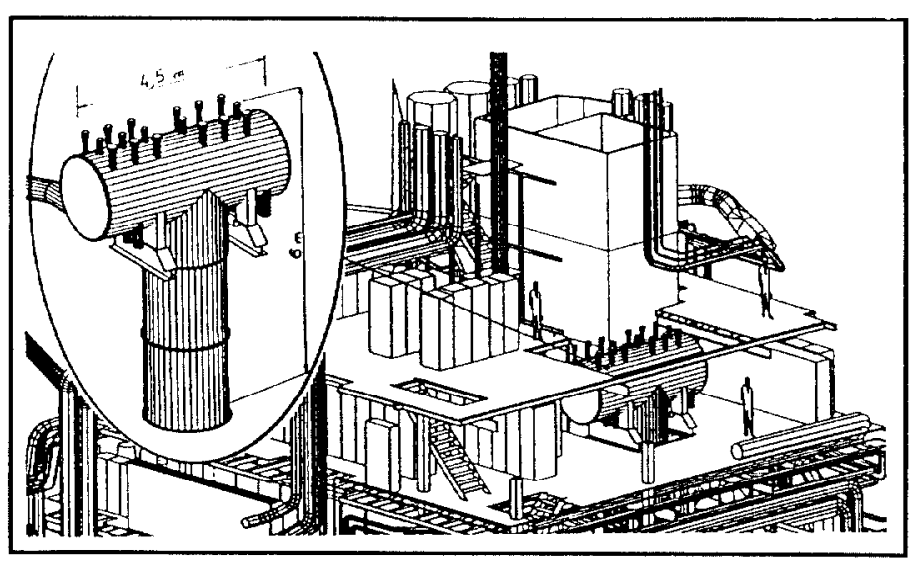

Figure 2

Integration of Lower Cold Box at bottom of LEP shaft
All components below $20 \mathrm{~K}$ were grouped into $\mathrm{T}$-shaped "Lower Cold Boxes" (LCB) for which a position could be found, amidst cable trays and ventilation ducts (Figure 2), in the steel structure at the lower end of the access shaft (typical weight $15 \mathrm{t}$, including 3 turbines).

The Upper and the Lower cold boxes had to be interconnected by vacuum-insulated transfer lines. The $20 \mathrm{~K}$ separation level turned out to be particularly convenient: at this temperature heat insulation is not very critical and gas density is low enough not to give static head problems and not to requirc big pipe diameters; only four respectively five interconnecting cold pipes were considered necessary: the two main HP and LP pipes, two screen gas pipes, and, in the solution adopted by L'AIR LIQUIDE, one bypass for specific cooldown modes.

Each cavity bath requiring about 2001 of LHe, a total of 160001 of LHe or $12000 \mathrm{Nm}^{3}$ of helium gas must be available at each LEP point with SC cavities. For ease of operation during shutdown periods, it was decided to rely on gas rather than liquid storage. Fifty vertical steel vessels were ordered (75 $\mathrm{m}^{3}, 20$ bar), mostly from RUZCHIMMASH (Russia) as a result of agreements between CERN and Russia.

The cold helium distribution is done by a pair of separate transfer lines, one for LHe supply $(65 \mathrm{~mm}$ inner bore and 25 bar design pressure for LHC service) and a second for the cold gas return (100 mm bore, 16 bar). Both contain also a 22 mm bore screen cooling pipe with helium gas circulating in the $50-75 \mathrm{~K}$ range, cooling a 'soft' radiation screen which is made by wrapping of aluminium strips between inner and outer layers of superinsulation and clamping the strips on the screen pipe at regular intervals.

The transfer line pairs for LEP points 2 and 6 with initially 32 cavities each $(2 \times 275 \mathrm{~m}$ length) were ordered from L'AIR LIQUIDE. The lines for LEP point 8 ( $2 \times 405 \mathrm{~m}$ length) were ordered from the Russian firm CRYOGENMASH.

\section{STATUS OF INSTALLATION AND COMMISSIONING}

\section{A. Cryoplants}

Of the two $6 \mathrm{~kW}$ plants, only the 7 turbine SULZER/LINDE plant was finally installed undergromnd at I.FP point 2, to cool the first cavity modules in LEP before the $12 \mathrm{~kW}$ plant will there be available. The $6 \mathrm{~kW}$ plant of L'AIR LIQUIDE (3/4 turbines) was installed in the SM18 test hall. Both plants were commissioned in spring 1992 and have since been running most of the time [5]. The SULZER/LINDE plant has a power factor ${ }^{1}$ of about $240 \mathrm{~W} / \mathrm{W}$, and the L'AIR LIQUIDE plant achieved $290 \mathrm{~W} / \mathrm{W}$ with only 3 turbincs. Reports on both plants will be given at the forthcoming CEC93 [6].

Two of the four $12 \mathrm{~kW}$ plants are presently in the process of commissioning, the two others are being installed. The LINDE $12 \mathrm{~kW}$ plant at point 6 was first priority for CERN and came already, during tests in April 1993 close to the

\footnotetext{
${ }^{1}$ expressed as ratio of total electric input to equivalent cooling power at $4.5 \mathrm{~K}$
} 
design performance and a record power factor of $220 \mathrm{~W} / \mathrm{W}$, as shown in Table 2.

Table 2 Results of first reception tests of $12 \mathrm{~kW}$ cryoplant supplied by LINDE [4]

\begin{tabular}{|lr|}
\hline Suction pressure of compressor set [bar] & 1.01 \\
Delivery pressure, compressor set [bar] & 19.8 \\
He mass flow [g/s] with suction gas at $295 \mathrm{~K}$ & 712 \\
Electrical input [kW] & 2600 \\
Cooling performance as specified: & \\
Refrigeration at $4.5 \mathrm{~K}[\mathrm{~kW}$ ] & 10 \\
Cold gas returned warm ('liquefaction load') [g/s] & 13 \\
Screen cooling power at $<75 \mathrm{~K}[\mathrm{~kW}]$ & 6.7 \\
\hline
\end{tabular}

\section{B. Cold Distribution Systems}

Transfer line systems for 32 cavities at each of the LEP points 2 and 6 have been installed by L'AIR LIQUIDE, partly in the machine and partly in service tunnels, totalling $275 \mathrm{~m}$ for $\mathrm{LHe}$ and $275 \mathrm{~m}$ for cold gas return at each point. Average losses to the $4.5 \mathrm{~K}$ pipes were measured, using helium gas circulation at $10-20 \mathrm{~K}$ to $0.9-1.0 \mathrm{~W} / \mathrm{m}$, including $2 \times 8$ unshielded flexible connections of $3.5 \mathrm{~m}$ length and cryogenic control valves on the manifolds.

At LEP point 8 , the $810 \mathrm{~m}$ of double transfer lines were built and installed by CRYOGENMASH. Good quality and installation speed were achieved and an identical system is now ordered for LEP point 4 . First results with the recently started $12 \mathrm{~kW}$ plant from L'AIR LIQUIDE gave about $0.9 \mathrm{~W} / \mathrm{m}$, here including losses in $2 \times 16$ unshielded flexible connections to the cavity modules and their cryogenic valves.

\section{Experience with cavity cooling circuits}

During the acceptance tests of cavities and assembled modules, the layout of the cryogenic piping and the cooling passages on accessories inside the cavity modules [3] have been submitted to extensive tests. This design had to take into account severe space constraints due to the planned arrangement of LHC magnets on top of the LEP ring and the slope of the LEP tunnel reaching $1.4 \%$. There was in particular no room for a satisfactory LHe buffer and phase separation volume above the cavity bath.

The module cryogenics worked in general up to expectations. A few corrections had to be made to cope with the presence of helium vapour and partial phase separation in the $10 \mathrm{~m}$ long 'liquid' manifold underneath the cavities; this is due to the heat input in the transfer line system and can reach $50 \%$ volume fraction. A continuing concern is the limited cooling capacity available for the inner conductor of the Higher Order Mode (HOM) coupler, where RF losses in normal operation are in the $\mathrm{mW}$ range but may reach several Watts during conditioning. Active cooling of the cables extracting the HOM power and of the beam pipe transition cones may have to be added to handle the losses expected when LEP will reach total beam current of $8 \mathrm{~mA}$ or more.

\section{CONCLUSIONS AND OUTLOOK}

The cryogenics for the LEP200 cavities had to be designed, ordered and built on a very short time scale. Competent suppliers could be found, and thanks to their effort and their willingness to accept the particular installation constraints in LEP, almost all required hardware has been installed in time and will be completed in early 1994 .

The slower initial pace of cavity module installation in the LEP tunnel is now giving the opportunity of doing a systematic running-in of the new $12 \mathrm{~kW}$ cryoplants and of developing fully satisfactory procedures and software for automatic operation from a remote control room. This control room is unattended outside normal working hours, but operators can be called in by an automatic paging system triggered by alarm signals from the plants.

A particular concern is the capability of a fast restart of the cryoplants after accidental stops (in most cases due to a failure of services [5]), to avoid downtime multiplication for LEP by quickly stopping the LHe evaporation to achieve a fast refilling of the cavities baths. A study [7] is under way to tind a satisfactory solution for the ' $\Delta \mathrm{T}$ ' problem of the biggest heat exchanger in the cryoplants where conservative temperature rules of the manufacturers prevent a quick restart, once cold helium evaporated from the liquid in the cold box and around the cavities has lowered the warm end temperature. An external bypass for the cold gas is installed, and at restart early reliquefaction and a modulated increase of high-pressure flow will be used to save LEP time without reaching dangerous stress levels in the heat exchangers.

Another line of action is the development of systematic preventive maintenance and failure analysis for the new plants to rapidly achieve the low failure rate known from smaller refrigerators [5].

\section{REFERENCES}

[1] C.Wyss, "Progress of the LEP Energy Upgrade Project", these proceedings

[2] C.Benvenuti et al., "Superconducting Cavities for the LEP200 Energy Upgrade", these proceedings

[3] M.Barranco-Luque et al., "Status of Cryogenics for the LEP200 Energy Upgrade Project at CERN", Cryogenics, Vol.32, ICEC Supplement, 151 (1992)

[4] B.Chromec et al., "A Highly Efficient $12 \mathrm{~kW}$ Helium Refrigerator for the LEP200 Project at CERN", Proceedings of IISSC, San Francisco, May 1993

[5] D.Delikaris et al., "Long-term Experience with Cryoplant Operation for Superconducting Magnets and RF Cavities at CERN", these proccedings

[6] CEC93 (Cryogenic Engineering Conference and International Cryogenic Materials Conference), Albuquerque, July 12-16, 1993

[7] G.Owren, "Rapid Temperature Change for Plate-Fin Heat Exchangers", CERN/AT-CR internal report 